\title{
Altered Responsivity to Central Administrations of Corticotropin-Releasing Factor in Rats With a History of Opiate Exposures
}

\author{
Kate E. Blatchford, Eun A. Choi, and Gavan P. McNally \\ University of New South Wales
}

\begin{abstract}
The authors studied the effects of a history of opiate exposures on behavioral responses to intracerebroventricular (ICV) microinjections of the stress-related peptide corticotropin-releasing factor (CRF). Rats were injected for 10 days with morphine $(10 \mathrm{mg} / \mathrm{kg})$ or saline, and 1 or 7 days later they received an ICV microinjection of CRF $(0.5 \mu \mathrm{g}$ or $2.5 \mu \mathrm{g})$ or artificial cerebrospinal fluid. Microinjections of CRF produced anxiety-like behavior, locomotor activity, and self-grooming. The anxiogenic response was altered so that morphine-treated rats showed reduced responses to $0.5-\mu \mathrm{g}$ CRF but showed exaggerated responses to $2.5-\mu \mathrm{g}$ CRF 1 or 7 days after last opiate exposure. These findings suggest that alterations in central CRF circuits may underpin the increased vulnerability to anxiety observed following opiate exposures.
\end{abstract}

Keywords: morphine, corticotropin-releasing factor, anxiety, locomotor activity, sensitization

There are bidirectional interactions between stress and drug dependence. Exposure to stressors potentiates the behavioral impacts of opiate and psychostimulants (e.g., Deroche et al., 1992) and facilitates drug self-administration (e.g., Goeders \& Guerin, 1994), drug withdrawal syndromes (e.g., McNally \& Lam, 2005), and relapse to drug-seeking (e.g., Shaham \& Stewart, 1995). Studies of human drug users reveal that stress and negative affect are potent antecedents to drug craving and relapse to drug-seeking (e.g., Shiffman et al., 1996). In animal models, a history of drug exposures can likewise increase vulnerability to stress (e.g., Blatchford, Diamond, Westbrook, \& McNally, 2005; Houshyar, Cooper, \& Woods, 2001; Houshyar, Gomez, Manalo, Bhargava, \& Dallman, 2003; Houshyar, Manalo, \& Dallman, 2004). For example, Blatchford et al. (2005) injected rats daily for 10 days with morphine or saline. Rats were then subjected to a 30-min restraint stressor. Restraint provoked tachycardia and a pressor response, anxiety-like behavior, and reduced exploration. In morphinetreated rats, the pressor response to restraint was reduced at 1 day, but not 7 days, after last opiate exposure. It is important to note that the anxiogenic effects of restraint stress were potentiated at 1 or 7 days after last opiate exposure.

Corticotropin-releasing factor (CRF) is an important mediator of behavioral, endocrine, and autonomic responses to stressors (Dunn \& Berridge, 1990). Microinjections of CRF produce anxiety-like behavior, behavioral activation, and self-grooming, whereas CRF antagonists prevent or reduce the anxiogenic effects of stressors (e.g., Dunn \& File, 1987; Heinrichs et al., 1994; Menzaghi et al.,

Kate E. Blatchford, Eun A. Choi, and Gavan P. McNally, School of Psychology, University of New South Wales, Sydney, Australia.

This research was supported by National Health and Medical Research Council of Australia Project Grant 209577 to Gavan P. McNally.

Correspondence concerning this article should be addressed to Gavan P. McNally School of Psychology, University of New South Wales, Sydney, New South Wales 2052, Australia. E-mail: g.mcnally@unsw.edu.au
1994; Stenzel-Poore, Heinrichs, Rivest, Koob, \& Vale, 1994). Prior research indicates that CRF plays an important role in the bidirectional interactions between stressors and psychostimulants CRF is critical for stress-induced relapse to cocaine seeking (Erb, Shaham, \& Stewart, 1998; Shaham, Erb, Leung, Buczek, \& Stewart, 1998), and a history of cocaine exposures increases behavioral responses to central injections of CRF (Erb, Funk, \& Le, 2003). These roles for CRF in arousal and emotionality, as well as evidence that prolonged exposures to psychostimulants increases responsivity to $\mathrm{CRF}$, raise the possibility that $\mathrm{CRF}$ contributes to the increased vulnerability to stress observed following opiate exposures. Previous findings that levels of CRF mRNA or peptide are increased in the amygdala and hypothalamus following prolonged exposures to opiates (e.g., Houshyar et al., 2003, 2004; Laorden, Milanes, Angel, Tankosic, \& Burlet, 2003; Maj, Turchan, Smialowska, \& Przewlocka, 2003; McNally \& Akil, 2002) are consistent with this possibility, as are recent data showing that exposures to opiates increases locus coeruleus (LC) neuronal responses to CRF (Xu, Van Bockstaele, Reyes, Bethea, \& Valentino, 2004). However, to date, there have been no investigations into the consequences for behavioral responsivity of these opiate-induced changes in the CRF system.

This experiment studied behavioral responses to central injections of CRF in rats with a history of opiate exposures. Intracerebroventricular (ICV) infusions of CRF are anxiogenic and produce a well-characterized behavioral activation and an increase in selfgrooming (Koob \& Heinrichs, 1999). The question of interest here was whether these effects of CRF are altered in rats with a history of opiate exposures. The design was a $2 \times 3 \times 2$ between-groups factorial. The first factor was drug history (history of morphine vs. saline injection). The second factor was type of ICV infusion given prior to test (artificial cerebrospinal fluid [aCSF], 0.5- $\mu \mathrm{g} \mathrm{CRF}$, or $2.5-\mu \mathrm{g} C R F$ ). The third factor was when rats were tested (1 or 7 days after last opiate exposure) for anxiety-like behavior, activity, and self-grooming. 


\section{Method}

\section{Subjects}

Subjects were 96 experimentally naive male Wistar rats weighing between 280 and $300 \mathrm{~g}$ at the start of the experiment. They were obtained from a commercial supplier (Gore Hill Research Laboratories, Sydney, Australia). Prior to surgery, rats were housed in groups of 8 in plastic cages $(60 \mathrm{~cm} \times 40 \mathrm{~cm} \times 22 \mathrm{~cm})$. After surgery, rats were singly housed in plastic cages $(40 \mathrm{~cm} \times 26 \mathrm{~cm} \times 16 \mathrm{~cm})$ and were handled daily. Rats were singly housed to prevent conspecifics from interfering with the intracranial cannulas. These cages were maintained in a colony room on a 12-hr light-dark cycle (lights on at 7:00 a.m.). All experiments were conducted during the day. The procedures used were approved by the University of New South Wales Animal Care and Ethics Committee.

\section{Surgery and Histology}

The procedure for surgery was identical to that described previously (McNally, Lee, Chiem, \& Choi, 2005). The right lateral ventricle was targeted so that the tip of the guide cannula was positioned $0.8 \mathrm{~mm}$ anterior, $1.5 \mathrm{~mm}$ lateral, and $4.0 \mathrm{~mm}$ ventral to bregma, with the incisor bar maintained at $3.3 \mathrm{~mm}$ below horizontal. At the conclusion of the experiment, rats were given an overdose of sodium pentobarbital and an ICV microinjection of 50- $\mu 1$ cresyl violet. Unfixed brains were sectioned coronally. An observer, unaware of the subject's group designation inspected the brains for the presence of stain. Only rats for which cresyl violet was present in the contralateral ventricle and in the third ventricle were included in the analysis.

\section{Apparatus}

Social interaction and activity were observed in plastic arenas $(40 \mathrm{~cm} \times$ $26 \mathrm{~cm} \times 16 \mathrm{~cm}$ ). The front of these arenas was constructed of Perspex, and the walls and floor were constructed of plastic. The roofs were constructed from stainless steel bars. The arenas were located individually within sound-attenuating cabinets that were painted black. The sound-attenuating cabinets were illuminated by a red LED light so that levels of illumination within the arenas were 15 candela $/ \mathrm{m}^{2}$. A digital camera was mounted on the rear wall of the sound-attenuating cabinets and was connected to a VCR in an adjacent laboratory.

\section{Drugs}

Rats were injected subcutaneously in the dorsal neck region daily for 10 days with morphine hydrochloride $(10 \mathrm{mg} / \mathrm{kg}$; a gift from GlaxoSmithKline, Sydney, Australia) or sterile nonpyrogenic saline $(0.9 \% \mathrm{wt} / \mathrm{vol})$. This injection regime was chosen because we have previously shown that it alters responsivity to restraint stress (Blatchford et al., 2005). All injections were in a volume of $1 \mathrm{ml} / \mathrm{kg}$. Rat CRF (Sigma, St Louis, MO) was dissolved in aCSF and infused at a dose of $0.5 \mu \mathrm{g}$ or $2.5 \mu \mathrm{g}$. aCSF was used for control microinjections. All microinjections were in a volume of $2.5 \mu 1$.

\section{Procedure}

Injections commenced 5 days after surgery. On the day before testing, rats were familiarized for $120 \mathrm{~min}$ with the test arena. The following day, rats were familiarized with the arena for a further $60 \mathrm{~min}$. Rats were then removed and given ICV microinjections according to group allocations. A 33 -gauge microinjection cannula was inserted into the guide cannula. The microinjection cannula projected a further $1 \mathrm{~mm}$ ventral to the tip of the guide cannula. The microinjection cannula was connected to a $25-\mu l$ glass syringe (Hamilton, Reno, NV) operated by a microinjection pump. Drugs were infused over a 3-min period, and the microinjection cannula left in place for a further $2 \mathrm{~min}$ to permit diffusion of the injectate. Twenty minutes later, rats were returned to the arena and tested for $10 \mathrm{~min}$ using the low-light, familiar apparatus version of the social-interaction test. This version was chosen because (a) it is maximally sensitive to anxiogenic manipulations (File \& Seth, 2003); (b) we were interested in studying behavioral activation following ICV microinjections of CRF, and these microinjections only produce behavioral activation when rats are tested in familiar chambers under conditions of low arousal (Koob \& Heinrichs, 1999); and (c) it is identical to the procedure used in previous experiments studying restraint stress (Blatchford et al., 2005). The test duration (10 min) is identical to that previously used by Blatchford et al. (2005) and similar to that used by others to study the anxiogenic effects of CRF (7.5 min; Dunn \& File, 1987). The social-interaction test was conducted with untreated, unfamiliar, unoperated weight-matched partner male rats (File \& Seth, 2003). Time spent in social interaction (sniffing, grooming, following, crawling over, crawling under, or passive contact with partner) was scored. In this test, a decrease in social interaction without a concomitant decrease in activity indicates an anxiogenic response (File \& Seth, 2003). Partner rats were then removed, and the experimental rat was allowed 60 min of free exploration (i.e., 30 to $90 \mathrm{~min}$ after ICV infusion). The behavior of each experimental rat was scored every $4 \mathrm{~s}$ during this $60 \mathrm{~min}$ for activity (locomotor activity, rearing), grooming, and sleeping. Prior research has shown that the effects of ICV CRF on activity are long lasting and that the impact of a history of cocaine exposures on such activity can be detected 90-120 min after CRF infusion (Erb et al., 2003).

\section{Data Analysis}

The amount of time (in seconds) spent in social interaction (sniffing, grooming, following, crawling over, crawling under, or in passive contact with partner) across the 10-min test was recorded. Locomotor activity, rearing, and grooming during the subsequent 60 -min test of activity was scored by an observer unaware of group allocations. The data were analyzed by planned orthogonal contrasts preserving the factorial design (i.e., morphine vs. saline history $\left[\Psi_{1}\right.$, Factor 1$]$; aCSF vs. $0.5 \mu \mathrm{g} / 2.5 \mu \mathrm{g}\left[\Psi_{1}\right]$ and $0.5 \mu \mathrm{g}$ vs. $2.5 \mu \mathrm{g}\left[\Psi_{2}\right.$, Factor 2$] ; 1$ day vs. 7 days test [ $\Psi_{1}$, Factor 3]).

\section{Results}

The data from 17 rats were excluded from the statistical analysis because of incorrect cannula placement (see Figure 1 for final group sizes). The top panel of Figure 1 shows mean and standard error of the mean $(S E M)$ of time spent in social interaction. There was an overall anxiogenic effect of ICV CRF, $F(1,68)=83.1$, $p<.05$, so that CRF-treated rats spent significantly less time in social interaction than aCSF-treated rats. There was no overall difference between CRF doses, $F(1,68)=3.4, p>.05$. There were no main effects of day, $F(1,68)<1, p>.05$, or drug history, $F(1,68)<1, p>.05$. There was a two-way interaction between day and $0.5-\mu \mathrm{g}$ versus $2.5-\mu \mathrm{g} \mathrm{CRF}, F(1,68)=7.8, p<.05$, indicating that the difference between these doses was greater at the 1-day test than at the 7-day test. Importantly, there was a significant two-way interaction between drug history and $0.5-\mu \mathrm{g}$ versus 2.5 - $\mu \mathrm{g} \mathrm{CRF}, F(1,64)=13.5, p<.05$. Follow-up tests confirmed that morphine-treated rats showed significantly less anxiety-like behavior than saline-treated rats following infusion of $0.5-\mu \mathrm{g}$ CRF, $F(1,68)=6.5, p<.05$, but showed significantly greater anxiety-like behavior following infusion of 2.5- $\mu \mathrm{g}$ CRF, $F(1,68)=7.0, p<.05$. There were no other significant two-way 


\section{Social Interaction}

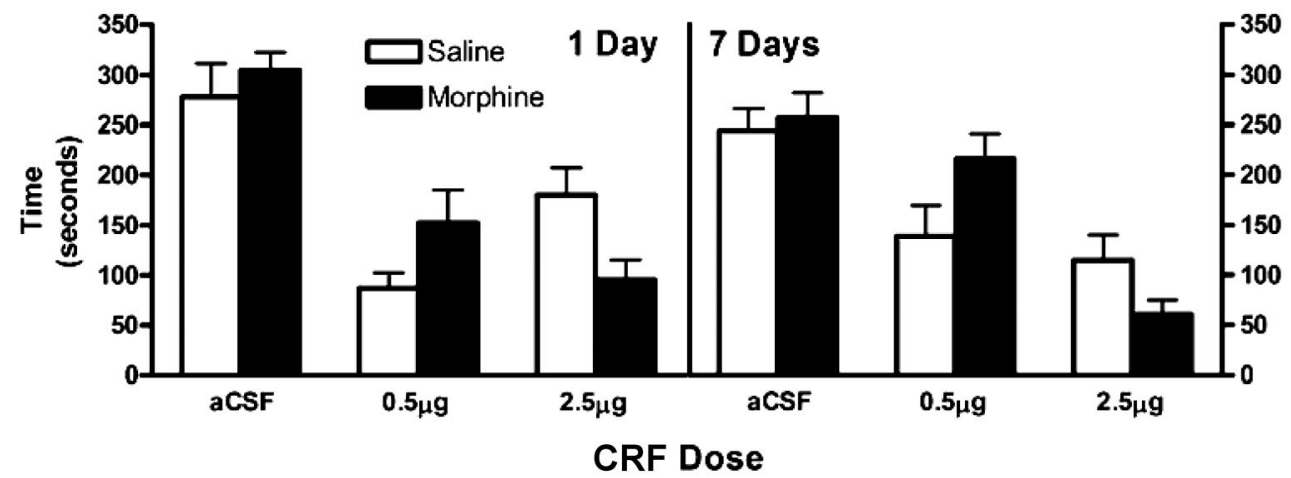

\section{Locomotor Activity}

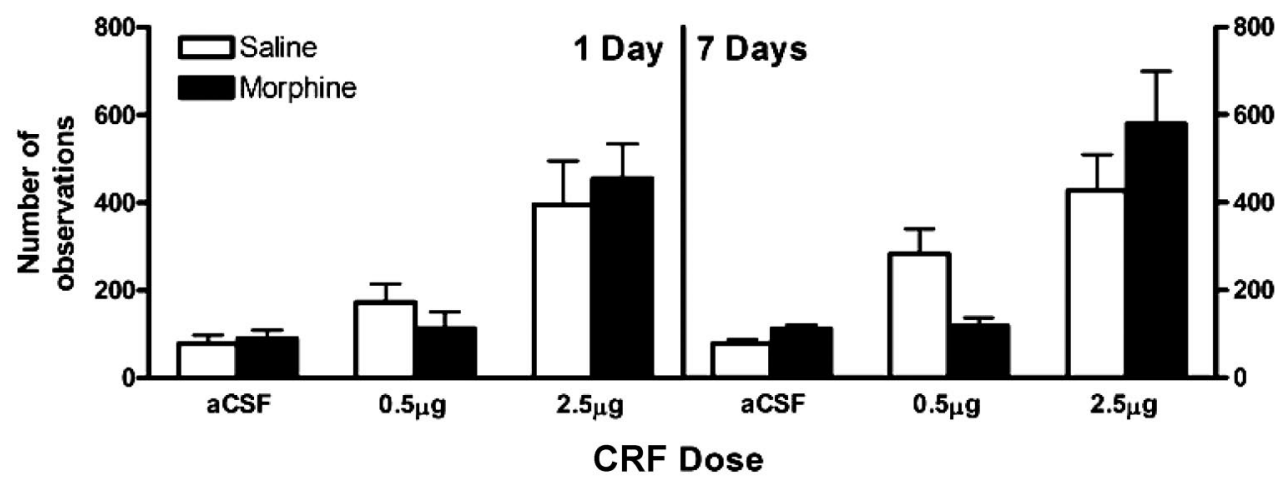

\section{Grooming}

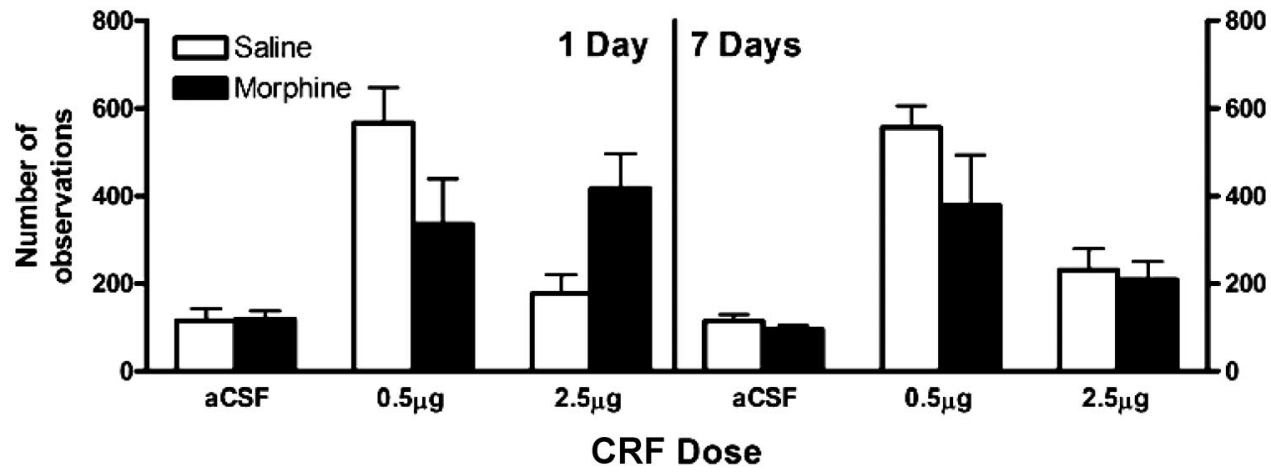

Figure 1. Top panel: Mean and standard error of time spent in social interaction following intracerebroventricular (ICV) infusions of artificial cerebrospinal fluid (aCSF), $0.5-\mu \mathrm{g}$ corticotropin-releasing factor (CRF), or 2.5 - $\mu \mathrm{g}$ CRF in rats with a history of morphine or saline injections tested 1 day (left panel) or 7 days (right panel) after last opiate exposure. Middle panel: Mean and standard error of observations scored as activity (locomotor activity and rearing) following ICV infusions of aCSF, $0.5-\mu \mathrm{g}$ CRF, or 2.5- $\mu \mathrm{g}$ CRF in rats with a history of morphine or saline injections tested 1 day (left panel) or 7 days (right panel) after last opiate exposure. Bottom panel: Mean and standard error of observations scored as self-grooming following ICV infusions of aCSF, 0.5- $\mu$ g CRF, or 2.5- $\mu$ g CRF in rats with a history of morphine or saline injections tested 1 day (left panel) or 7 days (right panel) after last opiate exposure. Saline 1 Day-aCSF $(n=8)$, morphine 1 Day-aCSF $(n=7)$, saline 1 Day-0.5- $\mu \mathrm{g}$ CRF $(n=6)$, morphine-1 Day 0.5- $\mu \mathrm{g}$ CRF $(n=6)$, saline-1 Day 2.5- $\mu$ g CRF $(n=6)$, morphine-1 Day 2.5- $\mu \mathrm{g}$ CRF $(n=7)$, saline 7 Days-aCSF $(n=$ 8), morphine 7 Days-aCSF $(n=8)$, saline 7 Days-0.5- $\mu$ g CRF $(n=5)$, morphine-7 Days 0.5- $\mu \mathrm{g}$ CRF $(n=6)$, saline-7 Days 2.5- $\mu$ g CRF $(n=6)$, morphine-7 Days 2.5- $\mu$ g CRF $(n=7)$. Error bars represent standard error. 
interactions, all $F \mathrm{~s}(1,68)<2.3, p>.05$, or three-way interactions, all $F \mathrm{~s}(1,68)<1, p>.05$.

The middle panel of Figure 1 shows the mean and SEM levels of activity (locomotor activity and rearing) during test. The data from the activity chamber for 4 rats at 1-day test (one from each of the following groups: saline-aCSF, saline-0.5- $\mu \mathrm{g}$ CRF, morphine-aCSF, and morphine-0.5- $\mu$ g CRF) was lost as a result of video recorder failure (removal of these rats from socialinteraction analysis did not alter the results). There was no main effect of day, $F(1,64)=1.6, p>.05$, or drug history, $F(1,64)<$ $1, p>.05$. There was an overall effect of ICV CRF on activity, $F(1,64)=35.2, p<.05$, so that these infusions increased activity. There was also an overall difference between $0.5-\mu \mathrm{g}$ and $2.5-\mu \mathrm{g}$ CRF, $F(1,64)=37.7, p<.05$, so that activity following $2.5-\mu \mathrm{g}$ CRF was significantly higher than that following $0.5-\mu \mathrm{g}$ CRF. There was a significant two-way interaction between drug history and $0.5-\mu \mathrm{g}$ versus $2.5-\mu \mathrm{g}$ CRF, $F(1,64)=5.2, p<.05$, indicating that morphine-treated rats were less responsive to $0.5-\mu \mathrm{g}$ CRF but were more responsive to $2.5-\mu \mathrm{g}$ CRF. However, follow-up tests indicated that, when averaged across days of test, the difference between morphine- and saline-treated rats was not significant at either $0.5-\mu \mathrm{g}, F(1,64)=2.5, p>.05$, or $2.5-\mu \mathrm{g}$ CRF, $F(1,64)=$ $2.7, p<.05$. There were no other significant two-way interactions, all $F \mathrm{~s}(1,64)<1, p>.05$, or three-way interactions, all $F \mathrm{~s}(1$, 64) $<1.1, p>.05$.

The bottom panel of Figure 1 shows the mean and SEM levels of grooming during test in the activity chamber. The analysis of variance revealed no overall difference between day of test, $F(1$, $64)<1, p>.05$. There was also no overall effect of drug history, $F(1,64)<1, p>.05$. There was an overall effect of ICV CRF on grooming, $F(1,64)=38.0, p<.05$, so that these infusions increased grooming. There was an overall difference between $0.5-\mu \mathrm{g}$ and $2.5-\mu \mathrm{g} \mathrm{CRF}, F(1,64)=16.5, p<.05$, so that grooming was significantly greater following $0.5-\mu \mathrm{g}$ versus $2.5-\mu \mathrm{g}$ CRF. There was a significant two-way interaction between drug history and $0.5-\mu \mathrm{g}$ versus $2.5-\mu \mathrm{g}$ CRF, $F(1,64)=9.9, p<$ .05 , indicating that morphine-treated rats were less responsive to $0.5-\mu \mathrm{g}$ CRF but more responsive to $2.5-\mu \mathrm{g}$ CRF. Follow-up tests indicated that the difference between morphine- and saline-treated rats was significant at $0.5-\mu \mathrm{g}, F(1,64)=7.6, p<.05$, but not at $2.5-\mu \mathrm{g}$ CRF, $F(1,64)=2.7, p<.05$. There were no other significant two-way interactions, $F(1,64)<1.1, p>.05$, or three-way interactions, all $F \mathrm{~s}(1,64)<1, p>.05$.

\section{Discussion}

These results show for the first time that a history of opiate exposures alters behavioral responses to the stress-related peptide CRF. Our results confirm that ICV CRF is anxiogenic, as measured by social interaction (Dunn \& File, 1987). A history of opiate exposures significantly altered this anxiogenic response: Morphine-treated rats were less responsive to the anxiogenic effects of a low dose but were more responsive to the anxiogenic effects of a high dose of CRF. These responses were similar regardless of whether rats were tested 1 or 7 days after last exposure to morphine. It is important to note that morphine- and saline-treated rats did not differ in their levels of anxiety-like behavior in the absence of ICV CRF. The results also confirm that
ICV CRF provokes behavioral activation and self-grooming (Koob $\&$ Heinrichs, 1999). There was some evidence that these activity and grooming responses were modulated by opiate exposures. In both cases, the history of opiate exposures interacted with the effects of $0.5-\mu \mathrm{g}$ versus $2.5-\mu \mathrm{g} \mathrm{CRF}$, indicating that morphinetreated rats were less responsive to the lower dose but were more responsive to the higher dose of CRF. The altered responses to CRF were obtained in rats subjected to passive (experimenteradministered) drug exposure. It will be of interest to determine whether similar alterations are observed following opiate self-administration.

These results identify CRF as critical to the bidirectional interactions between stress and opiate dependence. CRF mediates opiate withdrawal (e.g., McNally \& Akil, 2002) and relapse to opiate seeking (Shaham et al., 1998). The present results show that opiate-treated rats have altered responsiveness to the anxiogenic effects of CRF. The alteration in responsivity to the anxiogenic effects of the high dose of CRF is similar to that reported previously following restraint stress (Blatchford et al., 2005); exposure to either restraint stress or $2.5-\mu \mathrm{g}$ CRF provokes anxiety-like behavior that is exaggerated in rats with a history of opiate exposures. In this context, the reduction in the anxiogenic and selfgrooming effects of $0.5-\mu \mathrm{g}$ CRF is important because it shows that opiate exposures do not simply produce global increases in CRF responsiveness.

The mechanism and neuroanatomical locus for these alterations in CRF responsiveness are unclear. The amygdala is one important locus for the anxiogenic effects of CRF (Koob, 1999). Prolonged exposures to opiates upregulates CRF gene expression in the central nucleus of the amygdala (e.g., McNally \& Akil, 2002). These CRF neurons project to LC, and a history of opiate exposures can increase LC neuronal responses to CRF (Xu et al., 2004). Thus, one possibility is that the alteration in anxiogenic responses to CRF observed here, or the restraint stress reported previously (Blatchford et al., 2005), is due to alterations in the amygdala CRF-LC circuit. Another possibility is that opiate exposures altered levels of the CRF R1 receptor or the CRF binding protein, both of which influence responsiveness to CRF (DeSouza \& Grigoriadis, 1995). Such alterations have been documented following exposures to psychostimulants, so that prolonged exposures to cocaine can reduce CRF R1 binding (e.g., Ambrosio, Sharpe, \& Pilotte, 1997) and increase CRF binding protein expression (Erb, Funk, Borkowski, Watson, \& Akil, 2004) in the amygdala. However, these changes are typically short lived and do not persist beyond a few days after the last exposure to drugs. Further research is needed to address these possibilities.

It is worth commenting on the relationship between these results and those previously reported using restraint stress (Blatchford et al., 2005). Restraint stress and CRF have a common anxiogenic effect under the conditions tested here, and, as noted above, these are altered in rats with a history of opiate exposures. However, restraint stress and CRF have quite different impacts on activity and self-grooming under the conditions tested here. ICV CRF elicited a dose-dependent increase in activity, whereas restraint stress reduced activity. Likewise, ICV CRF produced a dosedependent increase in self-grooming, whereas restraint stress did not. There are two important points about these findings. First, they show that the overall behavioral impact of CRF is different to 
the overall behavioral impact of some stressors (see Dunn \& Berridge, 1990, for review). Second, these differences show that, under the conditions used here, there is little carryover between the tests for social interaction and those for activity. This means that the pattern of group differences observed during tests for activity are not likely due to prior testing for social interaction. Specifically, it could be suggested that the tests for activity and grooming are confounded by the immediately preceding test for social interaction. However, the finding that restraint stress and ICV CRF have similar effects in the social-interaction test but have opposite effects in tests for activity and grooming argues strongly against this possibility.

Our results complement recent findings of altered behavioral responsivity to CRF following exposure to psychostimulants. Prolonged exposure to cocaine sensitizes animals to the locomotor effects of CRF (Erb et al., 2003) and increases CRF-induced expression of c-fos mRNA in the central nucleus of the amygdala (Erb, Funk, \& Le, 2005). There is also evidence that prolonged exposures to ethanol can upregulate CRF in the amygdala (Lack, Floyd, \& McCool, 2005) and the hypothalamus (Li, Kang, Lee, \& Rivier, 2005). Although there are important differences in the behavioral consequences of histories of opiate (alterations in anxiogenic response to $\mathrm{CRF}$ ) and psychostimulant (increase in locomotor response to CRF) exposures, these and other findings (e.g., Ambrosio et al., 1997; Laorden et al., 2003; Maj et al., 2003; Richter, Pich, Koob, \& Weiss, 1995; Slawecki, Somes, \& Ehlers, 1999; Xu et al., 2004; Zhou et al., 1996) provide compelling evidence that alterations in central CRF circuits are a common neurobiological consequence of exposures to drugs of abuse (Kreek \& Koob, 1998).

In conclusion, we have shown for the first time that a history of opiate exposures alters behavioral responsivity to CRF. This finding may provide insights into understanding anxiety and emotionality in current and former human opiate users. Anxiety and stress-related disorders, especially posttraumatic stress disorder, are prevalent amongst human heroin users (e.g., Mills, Lynksey, Teesson, Ross, \& Darke, 2005). The present experiment raises the possibility that these disorders might emerge from opiate-induced dysregulation of central CRF circuits.

\section{References}

Ambrosio, E., Sharpe, L., \& Pilotte, N. (1997). Regional binding to corticotropin releasing factor receptors in brain of rats exposed to chronic cocaine and cocaine withdrawal. Synapse, 25, 272-276.

Blatchford, K. E., Diamond, K., Westbrook, R. F., \& McNally, G. P. (2005). Increased vulnerability to stress following opiate dependence: Behavioral and autonomic correlates. Behavioral Neuroscience, 119, 1034-1041.

Deroche, V., Piazza, P. V., Casolini, P., Maccari, S., Le Moal, M., \& Simon, H. (1992). Stress-induced sensitization to amphetamine and morphine psychomotor effects depend on stress-induced corticosterone secretion. Brain Research, 598, 343-348.

DeSouza, E. B., \& Grigoriadis, D. E. (1995). Corticotropin-releasing factor: Physiology, pharmacology, and the role in central nervous system and immune disorders. In F. E. Bloom \& D. J. Kupfer (Eds.), Psychopharmacology: The fourth generation of progress (pp. 505-517). New York: Raven.

Dunn, A. J., \& Berridge, C. W. (1990). Physiological and behavioral responses to corticotropin-releasing factor administration: Is CRF a mediator of anxiety or stress responses? Brain Research: Brain Research Reviews, 15, 71-100.

Dunn, A. J., \& File, S. E. (1987). Corticotropin-releasing factor has an anxiogenic action in the social interaction test. Hormones and Behavior, 21, 193-202.

Erb, S., Funk, D., Borkowski, S., Watson, S. J., \& Akil, H. (2004). Effects of chronic cocaine exposure on corticotropin-releasing factor binding protein in the central nucleus of the amygdala and bed nucleus of the stria terminalis. Neuroscience, 123, 1003-1009.

Erb, S., Funk, D., \& Le, A. D. (2003). Prior, repeated exposure to cocaine potentiates locomotor responsivity to central injections of corticotropinreleasing factor (CRF) in rats. Psychopharmacology, 170, 383-389.

Erb, S., Funk, D., \& Le, A. D. (2005). Cocaine pre-exposure enhances CRF-induced expression of c-fos mRNA in the central nucleus of the amygdala: An effect that parallels the effects of cocaine pre-exposure on CRF-induced locomotor activity. Neuroscience Letters, 383, 209-214.

Erb, S., Shaham, Y., \& Stewart, J. (1998). The role of corticotropinreleasing factor and corticosterone in stress- and cocaine-induced relapse to cocaine seeking in rats. Journal of Neuroscience, 18, 5529-5536.

File, S. E., \& Seth, P. (2003). A review of 25 years of the social interaction test. European Journal of Pharmacology, 463, 35-53.

Goeders, N. E., \& Guerin, G. F. (1994). Non-contingent electric footshock facilitates the acquisition of intravenous cocaine self-administration in rats. Psychopharmacology, 114, 63-70.

Heinrichs, S. C., Menzaghi, F., Pich, E. M., Baldwin, H. A., Rassnick, S., Britton, K. T., \& Koob, G. F. (1994). Anti-stress action of a corticotropin-releasing factor antagonist on behavioral reactivity to stressors of varying type and intensity. Neuropsychopharmacology, 11, 179-186.

Houshyar, H., Cooper, Z. D., \& Woods, J. H. (2001). Paradoxical effects of chronic morphine treatment on the temperature and pituitary-adrenal responses to acute restraint stress: A chronic stress paradigm. Journal of Neuroendocrinology, 13, 862-874.

Houshyar, H., Gomez, F., Manalo, S., Bhargava, A., \& Dallman, M. F. (2003). Intermittent morphine administration induces dependence and is a chronic stressor in rats. Neuropsychopharmacology, 28, 1960-1972.

Houshyar, H., Manalo, S., \& Dallman, M. F. (2004). Time-dependent alterations in mRNA expression of brain neuropeptides regulating energy balance and hypothalamo-pituitary-adrenal activity after withdrawal from intermittent morphine treatment. Journal of Neuroscience, 24, 9414-9424.

Koob, G. F. (1999). Corticotropin-releasing factor, norepinephrine, and stress. Biological Psychiatry, 46, 1167-1180.

Koob, G. F., \& Heinrichs, S. C. (1999). A role for corticotropin releasing factor and urocortin in behavioral responses to stressors. Brain Research, 848, 141-152.

Kreek, M. J., \& Koob, G. F. (1998). Drug dependence: Stress and dysregulation of brain reward pathways. Drug and Alcohol Dependence, 51, $23-47$.

Lack, A. K., Floyd, D. W., \& McCool, B. A. (2005). Chronic ethanol ingestion modulates proanxiety factors expressed in rat central amygdala. Alcohol, 36, 83-90.

Laorden, M. L., Milanes, M. V., Angel, E., Tankosic, P., \& Burlet, A. (2003). Quantitative analysis of corticotropin-releasing factor and arginine vasopressin mRNA in the hypothalamus during chronic morphine treatment in rats: An in situ hybridization study. Journal of Neuroendocrinology, 15, 586-591.

Li, Z., Kang, S. S., Lee, S., \& Rivier, C. (2005). Effect of ethanol on the regulation of corticotropin-releasing factor (CRF) gene expression. Molecular and Cellular Neurosciences, 29, 345-354.

Maj, M., Turchan, J., Smialowska, M., \& Przewlocka, B. (2003). Morphine 
and cocaine influence on CRF biosynthesis in the rat central nucleus of amygdala. Neuropeptides, 37, 105-110.

McNally, G. P., \& Akil, H. (2002). Role of corticotropin-releasing factor in the amygdala and bed nucleus of the stria terminalis in the behavioral, pain modulatory, and endocrine consequences of opiate withdrawal. Neuroscience, 112, 605-617.

McNally, G. P., \& Lam, S. (2005). Altered vulnerability to acute opiate withdrawal following stress: Roles of N-methyl-D-aspartate and glucocorticoid receptors. Behavioral Neuroscience, 119, 1215-1221.

McNally, G. P., Lee, B., Chiem, J. Y., \& Choi, E. A. (2005). The midbrain periaqueductal gray and fear extinction. Opioid receptor subtype and roles of cAMP, protein kinase A, and mitogen-activated protein kinase. Behavioral Neuroscience, 119, 1023-1033.

Menzaghi, F., Howard, R. L., Heinrichs, S. C., Vale, W., Rivier, J., \& Koob, G. F. (1994). Characterization of a novel and potent corticotropinreleasing factor antagonist in rats. Journal of Pharmacology and Experimental Therapeutics, 269, 564-572.

Mills, K. L., Lynskey, M., Teesson, M., Ross, J., \& Darke, S. (2005). Post-traumatic stress disorder among people with heroin dependence in the Australian treatment outcome study (ATOS): Prevalence and correlates. Drug and Alcohol Dependence, 77, 243-249.

Richter, R. M., Pich, E. M., Koob, G. F., \& Weiss, F. (1995). Sensitization of cocaine-stimulated increase in extracellular levels of corticotropinreleasing factor from the rat amygdala after repeated administration as determined by microdialysis. Neuroscience Letters, 187, 169-172.

Shaham, Y., Erb, S., Leung, S., Buczek, Y., \& Stewart, J. (1998). CP154,526 , a selective, non-peptide antagonist of the corticotropinreleasing factor 1 receptor attenuates stress-induced relapse to drug seeking in cocaine- and heroin-trained rats. Psychopharmacology, 137, 184-190.
Shaham, Y., \& Stewart, J. (1995). Stress reinstates heroin-seeking in drug-free animals: An effect mimicking heroin, not withdrawal. Psychopharmacology, 119, 334-341.

Shiffman, S., Hickcox, M., Paty, J. A., Gnys, M., Kassel, J. D., \& Richards. T. J. (1996). Progression from smoking lapse to relapse: Predictions from abstinence violation effects, nicotine dependence, and lapse characteristics. Journal of Consulting and Clinical Psychology, 64, 9931002.

Slawecki, C. J., Somes, C., \& Ehlers, C. L. (1999). Effects of chronic ethanol exposure on neurophysiological responses to corticotropinreleasing factor and neuropeptide Y. Alcohol and Alcoholism, 34, 289 299.

Stenzel-Poore, M. P., Heinrichs, S. C., Rivest, S., Koob, G. F., \& Vale, W. W. (1994). Overproduction of corticotropin-releasing factor in transgenic mice: A genetic model of anxiogenic behavior. Journal of Neuroscience, 14, 12579-12584.

Xu, G. P., Van Bockstaele, E., Reyes, B., Bethea, B., \& Valentino, R. J. (2004). Chronic morphine sensitizes the brain norepinephrine system to corticotropin-releasing factor and stress. Journal of Neuroscience, 24, 8193-8197.

Zhou, Y., Spangler, R., LaForge, K., Maggos, C., Ho, A., \& Kreek, M. J. (1996). Corticotropin-releasing factor and type 1 corticotropin-releasing factor receptor messenger RNAs in rat brain and pituitary during "binge"-pattern cocaine administration and chronic withdrawal. Journal of Pharmacology and Experimental Therapeutics, 279, 351-358.

Received February 1, 2006

Revision received June 19, 2006

Accepted July 5, 2006 